\title{
Now more than ever: World Health Assembly revisits primary health care
}

Primary health care, with nurses, midwives, family physicians and other allied health providers, is essential for the health of people (Starfield et al., 2005). The strength of primary health care is to respond to the local needs of individuals, families and populations. This focus on the prevailing conditions in the community has an impact on society beyond health itself, reducing social inequity and improving coherence (Shi et al., 2002). For many years, the World Health Organization (WHO) had promoted the concepts of primary health care and community orientation, but after the optimism of 'Health for All' and the 1978 Alma Ata Declaration (WHO, 1978), the political ambitions became wornout. The concept of organizing health care from a community basis and from a generalist perspective did ask a lot in terms of collaboration and coordination. It was an example of a 'grand design,' and 'grand designs' did fall from political favor in the 1980s and 1990s with the emphasis on liberalism and free enterprise. The market was to replace grand governmental designs, with competition, regulatory coordination and collaboration.

On the eve of the 30th anniversary of Alma Ata, the WHO launched its comeback when it made primary health care the focus of the 2008 World Health report (WHO, 2008a). And with the unanimous adoption during the May 2009, the World Health Assembly of the resolution 'Primary Health Care, including Health System Strengthening' (WHO, 2009), primary health care is back at the top of the political health care agenda.

\section{The 2009 resolution on primary health care: primary health care and public health}

Although the 2009 resolution does reiterate a number of the basic concepts of 1978 declaration, there are interesting differences. The first is the call to place people at the center of health care. With this plea for person centredness of health

C) Cambridge University Press 2009 care and medicine, the individual dimension comes forward. At the same time, the resolution refers to the social determinants of health (WHO, 2008b) as an important focus of primary health care, and this stresses the interface between public health and (individual) primary health care to improve the health of people (van Weel et al., 2008). In line with this, the resolution stresses the importance to reorganize disease- or health problem-specific (vertical) actions through comprehensive (horizontal) primary health care (De Maeseneer et al., 2008). The most powerful aspect of the resolution, though, is where it stresses 'to train and retain adequate numbers of health workers, with appropriate skill mix, including primary health care nurses, midwives, allied health professionals and family physicians, able to work in a multidisciplinary context, in cooperation with non-professional community health workers in order to respond effectively to people's health needs' (WHO, 2009). This specifies the professionals that form the primary health care team and gives them a face, and with it, impact.

\section{From Alma Ata 1978 to Geneva 2009: not just lost opportunities}

Behind the satisfaction of the reactivation of primary health care looms concern of its failure to deliver on its first promotion at Alma Ata. Therefore, it is important to compare the (professional) circumstances of 1978 and 2009. And in this comparison, it is striking how different these circumstances in fact are - in terms of professional development, in education and training and in science and research. In the world of 1978, only a handful of countries could boast well-developed primary health care to draw empirical data from. And even though there were academic organizations of general practice/family medicine in a number of countries at that time, international organizations such as the World Organization of 
Family Doctors, Wonca (Wonca, 2002) - essential to encompass the global dimension of primary health care - were in their infancy. Virtually, all teaching, education and training at that time was hospital based with at best a small role for the communitybased programmes. And probably most significantly, the first substantial evidence of the contribution of primary health care to peoples' health was published 15 years after the adoption of the Declaration (Starfield, 1994). In fact, it would not be an exaggeration to state that the Alma Ata Declaration of 1978 (WHO, 1978) had a profound effect on professional development, medical and paramedical education and training and research. This is, in fact, exemplified by the rich models of good primary care practice that the 2008 World Health Report (WHO, 2008a) was able to identify. It is difficult to overestimate the importance - to give just one example - of the development of a classification of health problems in the primary care and community setting (Wonca, 1998), when professionals are expected to respond to the community needs.

\section{Conclusion: from the conference room to the community and the consultation room}

It is important to keep these lessons of the postAlma Ata era alive. The development of health and health care policy has to go in close liaison with education and research. And professional development around the world has yielded substantial empirical examples of success to capitalize on. The interaction of public health and individual primary health care looks currently well covered on the research and development agenda, for the long march that lies ahead. Even more challenging is the interface of primary health care and (sub)specialty care. In the debate on health for people and populations, the evidence of the added contribution of subspecialties' care has been suspiciously absent. It is counter intuitive to assume that there is no value in the (sub)specialty developments of the past decades, but to be able appreciate it, there is a need to analyze it in the context of people and populations, rather than diseases and interventions in isolation, and to reason from the generic to the particular rather than the other way round. It is more than likely that (sub)specialty care will have the greatest impact when provided in a communitybased primary care context. This, it looks likely, is the ultimate challenge that the 2009 World Health Assembly has posed with its unanimous support for the resolution on primary health care.

Chris van Weel Professor of Family Medicine Department of Primary and Community Care Radboud University Nijmegen Medical Centre 117-HAG, PO BOX 9101, 6500 HB Nijmegen

The Netherlands

President World Organization of Family

Doctors, Wonca

Email: c.vanweel@elg.umcn.nl

Jan De Maeseneer

Professor of Family Medicine and Primary Health Care

Ghent University

U.Z. - 1K3, De Pintelaan 185 B-9000 Gent, Belgium

Chairman European Forum for Primary Care (www.euprimarycare.org) Email: Jan.DeMaeseneer@Ugent.be

\section{References}

De Maeseneer, J., van Weel, C., Egilman, D., Mfenyana, K., Kaufman, A., Sewankambo, N. and Flinkenflögel, M. 2008: Funding for primary health care in developing countries. Money from disease specific projects could be used to strengthen primary care. British Medical Journal 336, 518-19.

Shi, L., Starfield, B., Politzer, R. and Regan, J. 2002: Primary care, self-rated health, and reductions in social disparities in health. Health Services Research 37, 529-50.

Starfield, B. 1994: Is primary care essential? Lancet 344, 129-33.

Starfield, B., Shi, L. and Macinko, J. 2005: Contribution of primary care to health systems and health. Milbank Quarterly 83, 457-502.

van Weel, C., De Maeseneer, J. and Roberts, R. 2008: Integration of personal and community health care. Lancet 372, 871-72.

WHO. 1978: Declaration of Alma-Ata International Conference on Primary Health Care, Alma-Ata, USSR, 6-12 September 1978. Geneva: World Health Organization. Retrieved 27 July 2009 from http://www.who.int/ publications/almaata_declaration_en.pdf

WHO. 2008a: The World Health Report 2008: Primary Health Care - now more than ever. Geneva: World Health Organization. Retrieved 27 July 2009 from http://apps. who.int/bookorders/anglais/detart1.jsp?sesslan $=1 \&$ codlan $=$ $1 \& \operatorname{codcol}=24 \& \operatorname{codcch}=2008$ 
WHO. 2008b: Commission on social determinants of health. Closing the gap in a generation: health equity through action on the social determinants of health. Geneva: World Health Organization.

WHO. 2009: Primary health care, including health system strengthening. Geneva: World Health Organization, WHA resolution 62.12 .
Wonca, International Classification Committee. 1998: International classification of primary care, ICPC-2, second edition. Oxford: Oxford University Press.

Wonca, The World Organization of Family Doctors. 2002: What's in a name? "Wonca" explained. Retrieved 27 October 2009 from http://www.globalfamilydoctor.com/ aboutWonca/aboutwonca.asp?refurl5aw 